\title{
Preparation and Characterization of Spray-Dried Inhalable Powders Containing Polymeric Micelles for Pulmonary Delivery of Paclitaxel in Lung Cancer
}

\author{
Mahboubeh Rezazadeh ${ }^{1}$, Zahra Davatsaz $^{2}$, Jaber Emami ${ }^{2}$, Farshid Hasanzadeh $^{2}$, Ali Jahanian-Najafabadi ${ }^{3}$
}

${ }^{1}$ Department of Pharmaceutics and Novel Drug Delivery System Research Center, School of Pharmacy and Pharmaceutical Sciences, Isfahan University of Medical Sciences, Isfahan. ${ }^{2}$ Department of Pharmaceutics, School of Pharmacy and Pharmaceutical Sciences, Isfahan University of Medical Sciences, Isfahan. ${ }^{3}$ Department of Pharmaceutical Biotechnology, School of Pharmacy and Pharmaceutical Sciences, Isfahan University of Medical Sciences, Isfahan.

Received, June 28, 2018; Accepted, August 25, 2018; Published, August 27, 2018.

\begin{abstract}
Purpose: Local delivery of chemotherapeutic drugs to the lungs offers many advantages for lung cancer treatment compared to conventional systemic chemotherapy. In the present study, novel mixed polymeric micelles based on tocopheryl succinate-polyethylene glycol 1000 and $5000 \mathrm{Da}\left(\mathrm{TPGS}_{1 \mathrm{~K}}\right.$ and $\mathrm{TPGS}_{5 \mathrm{~K}}$ ) were synthesized and loaded with paclitaxel (PTX). Then, the optimized micelles were incorporated as colloidal drug delivery system into lactose carrier particles using a spray drying technique. Methods: The mixed micelles of TPGS $_{5 \mathrm{~K}}$ and $\mathrm{TPGS}_{1 \mathrm{~K}}$ in different molar ratios $(10: 0,7: 3,5: 5,3: 7,0: 10)$ were prepared and physicochemical properties including: particle size, zeta potential, critical micelle concentration (CMC), drug loading, drug release rate, and in vitro cytotoxicitywere investigated in details. The optimized nanoparticles were co-spray dried with lactose carriers to produce the spherical particle morphology of the inhalable particles. Results: Particle sizes and zeta potentials of the different formulations varied in the range of 102 to $196 \mathrm{~nm}$ and -9.4 to $-13.8 \mathrm{mV}$, respectively. The lowest CMC values were calculated for 5:5 and 7:3 combinations $(16.33$ and $17.89 \mu \mathrm{M}$, respectively). The drug release rate from different formulations were very slow and only $30 \%$ of the drug was released during $72 \mathrm{~h}$. Cytotoxicity assay demonstrated increased cytotoxic activity of PTX-loaded mixed micelles compared to the free drug. The in vitro deposition data indicated that spray drying of PTX-loaded micelles with lactose resulted in the production of inhalable powders with the high fine particle fraction (60\%). Conclusion: These results demonstrate that this novel PTX-loaded micelles embedded in dry powder inhalation aerosol platform has a great potential to be used in lung cancer treatment.
\end{abstract}

\section{INTRODUCTION}

Local delivery of drugs to the lungs is highly desirable for the treatment of pulmonary diseases such as lung cancer, tuberculosis, chronic obstructive pulmonary diseases, asthma, and other respiratory infections [1]. The main advantages of the local treatment of pulmonary disorders include rapid onset of action, higher drug concentrations at the site of action, lower dose requirements, and fewer systemic side effects [1,2]. In addition, if local pulmonary administration is accompanied with the sustained release property, the therapeutic outcomes of a drug could be efficiently enhanced. Sustained release of drugs in the lungs might result in favorable therapeutic index by prolonging residence time at the target site, reducing its side effects, and enhancing patient compliance [3]. Regional delivery of cytotoxic drugs has been recently proposed as a promising treatment strategy for lung cancer.
Inhalation of chemotherapeutic agents in primary or metastatic lung cancer, could enhance exposure of tumor cells to the drug while minimize systemic side effects [3]. Some animal studies have demonstrated the pharmacokinetic advantages and anti-tumor effect of aerosol delivery of chemotherapeutic solutions such as paclitaxel (PTX) and doxorubicin $[4,5]$. However, regional toxicity is the main obstacle for clinical application of inhaled solution of cytotoxic agents. In recent years, there is an increasing interest in the development of inhalable nanocarriers for lung cancer treatment. Nanocarriers such as liposomes, nanoparticles, and polymeric micelles are able to encapsulate lipophilic cytotoxic drugs resulting in reduction of drug- associated

\footnotetext{
Corresponding Author: Jaber Emami, Department of Pharmaceutics, School of Pharmacy and Pharmaceutical Sciences, Isfahan University of Medical Sciences, Isfahan, Email: emami@pharm.mui.ac.ir.
} 
toxicity and accumulation of their cargo in cancer tissue via enhanced permeation and retention (EPR) effect [6-8]. Moreover, mucociliary clearance and macrophages phagocytosis can be overcome by using nano-size systems [4]. However, one limitation of nano-size carriers for pulmonary delivery of drugs is that their sizes are not suitable for deep lung deposition and they are easily exhaled from the respiratory tract [9]. The most common approach to proper inhalable powders is using a carrier system such as lactose or manitol microparticles. These carbohydrates are non-toxic, readily degradable and approved by Food and Drug Administration (FDA) as excipients for inhalation purposes [9]. The carrier particles should ensure an appropriate mass median aerodynamic diameter (MMAD) and a suitable fine particle fraction (FPF) for a maximum alveolar deposition of the embedded drugs at normal inhalation rates. Carrier particles are dissolved after coming in contact with the aqueous medium and release the nanoparticles. Azarmi et al. developed doxorubicin-loaded nanoparticles and incorporated into lactose carriers using a sprayfreeze-drying technique [10]. They demonstrated the incorporation of nanoparticles did not affect the FPF or MMAD of the microparticles. In another study hematoporphyrine was encapsulated into polymeric micelles and subsequently incorporated into lactose carriers by spray drying [11]. The results revealed that the micelles remained stable after dissolution of the lactose microparticles [11]. Armita and coworkers investigated the in-vitro deposition pattern of cisplatin from dry powder containing the drugloaded gelatin nanoparticles [12]. They demonstrated the possibility of delivering the nanoparticles to the lungs by incorporating them into carrier particles by simple freeze drying technique [12]. PTX is extensively used for the treatment of a broad spectrum of cancers specially breast, ovarian, and non-small lung cancers [13]. Thus, PTX represents one of the best candidates to be delivered into the lungs. Alipour et al, fabricated alginate microparticles for pulmonary delivery of PTX [14]. The in vitro release profile demonstrated slow release rate of PTX from microparticles and the drug-loaded particles inhibited the growth of human non-small cell lung cancer cell line A549 [14]. However, these microparticles due to their large particle sizes would be rapidly taken up by alveolar macrophages and that is the major practical challenge in clinical application of polymeric microparticles for pulmonary delivery. In vitro studies have demonstrated that using nano-size carriers could prevent macrophages phagocytosis and enhance efficient drug uptake by epithelial and cancer cells [15-17]. For instances, in the work conducted by Gill et al, [17], intratracheally administered PTX-loaded polymeric micelles showed higher accumulation of PTX in the lungs and lower content of the drug to non-targeted organs compared to intravenously administered formulation. In other similar studies, solid lipid nanoparticles, liposomes and polymeric nanoparticles were investigated for pulmonary delivery of PTX [18-20]. In all aforementioned studies, the nanoparticles were used intratracheally which could not be applied clinically. In the current study, we aimed to formulate a dry powder particulate system embedding PTX-loaded polymeric micelles suitable for pulmonary delivery. Here we fabricated polymeric micelles from the mixture of two different molecular weights, 1000 and $5000 \mathrm{Da}$, of $\alpha$-tocopheryl polyethylene glycol succinate $\left(\mathrm{TPGS}_{1 \mathrm{~K}}\right.$ and $\left.\mathrm{TPGS}_{5 \mathrm{~K}}\right)$. TPGS $\mathrm{T}_{1 \mathrm{~K}}$, a watersoluble derivative of natural vitamin $\mathrm{E}$, is synthesized by esterification of $\alpha$-tocopheryl succinate $(\alpha-T S)$ with polyethylene glycol 1000 (PEG) and has been approved by FDA as a safe pharmaceutical adjuvant used in drug formulation. $\mathrm{TPGS}_{1 \mathrm{~K}}$ has an amphiphilic structure which forms micelles in aqueous media. PTX has a high solubility in $\alpha$-TS $(11 \mathrm{mg} / \mathrm{mL})$ which enhances polymer-drug miscibility thereby improving drug loading into the micelles [21]. It has also been found that $\mathrm{TPGS}_{1 \mathrm{~K}}$ could inhibit drug efflux pumps or p-glycoproteins (p-gp) meditated multi-drug resistance, thus facilitates permeation of the drugs to the cells and greatly enhances the therapeutic effects of antitumor agents. In addition, TPGS could effectively inhibit the growth of cancer cells by its ability to induce apoptosis [21,22]. Despite the unique advantages, $\mathrm{TPGS}_{1 \mathrm{~K}}$ has a high CMC value $(0.12 \mathrm{mg} / \mathrm{mL})$, which decreases the stability of micelles in physiological environment. Thus, till now, $\mathrm{TPGS}_{1 \mathrm{~K}}$ has been usually used together with other lipids or synthetic copolymers to form micelles and the presence of $\mathrm{TPGS}_{1 \mathrm{~K}}$ in the micelles has greatly improved the drug encapsulation efficiency and decreased the release rate of loaded drugs [23,24]. In this work, we synthesized a new TPGS $_{5 \mathrm{k}}$ amphiphilic polymer via reaction between $\alpha$-TS and methoxy PEG of molecular weight 5000 (MePEG5000). The new synthesized TPGS ${ }_{5 \mathrm{k}}$ showed much lower CMC value compared with the traditional TPGS ${ }_{1 K}$. This change 
makes it possible to form stable micelles by TPGS alone without any other polymers or lipids. Therefore, this work focuses on synthesis of TPGS $_{5 \mathrm{k}}$ which are mixed with $\mathrm{TPGS}_{1 \mathrm{~K}}$ to form micelles and solubilize PTX. The drug-loaded optimized formulation are subsequently entrapped in lactose microparticles to render them suitable for pulmonary delivery. The physicochemical properties of the micelles and carriers are investigated in details. Moreover, the in vitro cytotoxicities of the different formulations are evaluated and compared with Stragen ${ }^{\circledR}$ (commercial formulation of PTX in Cremophor $^{\mathbb{B}}$ EL) against human lung cancer cell line, A549.

\section{METHODS AND MATERIALS}

\section{MATERIALS}

$\alpha$-Tocopheryl polyethylene glycol 1000 succinate $\left(\mathrm{TPGS}_{1 \mathrm{~K}}\right.$ ) was purchased from Eastman Co. (USA). Paclitaxel (PTX), methoxypolyethylene glycol (MePEG, $\left.\mathrm{M}_{\mathrm{W}}=5000 \quad \mathrm{Da}\right)$, dicyclohexylcarbodiimide (DCC), 4(dimethylamino) pyridine (DMAP), pyrene, anhydride dimethyl sulfoxide (DMSO), and anhydrous dichloromethane (DCM) were purchased from Sigma Chemical Co. (St. Louis, MO). HPLCgrade methanol and acetonitrile were supplied by Caledon (Ontario, Canada). Paclitaxel Stragen ${ }^{\circledR}$ (30 $\mathrm{mg} / 5 \mathrm{~mL}$ ) was provided by Sobhan Oncology (Rasht, Iran). Dulbecco's Modified Eagle's Medium/Nutrient Mixture F-12 Ham (DMEM/F12), fetal bovine serum (FBS) and antibiotics for cell culture were provided by Sigma-Aldrich (St. Louis, MO). Human non-small cell lung cancer cell line (A549) was obtained from Pasteur institute of Iran (Tehran, Iran). 3-(4,5-Dimethylthiazol-2-yl)-2,5diphenyltetrazolium bromide (MTT) was supplied by Sigma-Aldrich.

\section{METHODS}

\section{Synthesis of TPGS ${ }_{5 K}$}

TPGS $_{5 \mathrm{~K}}$ was synthesized through the reaction of activated carboxyl group of D- $\alpha$-tocopheryl succinate $(\alpha-T S)$ and hydroxyl group of MePEG in the presence of DCC and DMAP. Briefly, $\alpha$-TS (265 $\mathrm{mg}, 0.5 \mathrm{mmol}$ ), DCC (206 mg, $1 \mathrm{mmol}$ ), and DMAP (30.5 mg, $0.25 \mathrm{mmol}$ ) were dissolved in anhydrous DCM and stirred under nitrogen for $24 \mathrm{~h}$ in dark to activate the carboxyl group of $\alpha$-TS. The solution of
MePEG (500 mg, $0.1 \mathrm{mmol}$ ) in DCM was added into the activated $\alpha$-TS solution and the reaction mixture was stirred for $48 \mathrm{~h}$ under nitrogen. The mixture was then dialyzed against ethanol for $48 \mathrm{~h}$ to remove unreacted $\alpha$-TS, followed by dialysis against water for $24 \mathrm{~h}$ using dialysis membrane (MWCO: $2 \mathrm{kDa}$, Viskase Companies Inc., Darien, IL) and lyophilized to get pure $\mathrm{TPGS}_{5 \mathrm{~K}}$ powder (Freeze Dryer Model ALPHA 2-4 LD plus, Christ Company, Stuttgart, Germany). The chemical structure of $\mathrm{TPGS}_{5 \mathrm{~K}}$ was identified and calculated by ${ }^{1} \mathrm{H}-\mathrm{NMR}$ (Bruker, Biospin, AC-400, Mannheim, Germany) and Fourier transform infrared (FT-IR) (WQS-510/520, Raileigh, China) spectra.

\section{Preparation of the blank and PTX-loaded micelles}

To prepare empty mixed micelles, $\mathrm{TPGS}_{5 \mathrm{~K}}$ alone or in mixture with $\mathrm{TPGS}_{1 \mathrm{~K}}$ at different molar ratios (10:0 to 0:10) was dissolved in DCM and the organic solvent was then removed by rotary vacuum evaporation. The resultant film was hydrated with a suitable volume of deionized water, incubated at 37 ${ }^{\circ} \mathrm{C}$ for $30 \mathrm{~min}$, and then sonicated for a few minutes. The drug-loaded polymeric micelles were prepared by dissolving $3 \mathrm{mg}$ PTX in DCM which was then added to $10 \mathrm{mg}$ polymer mixture already dissolved in DCM [21]. The micelle preparation steps described above were exactly repeated. The PTXloaded micellar solution was then centrifuged at $7000 \mathrm{rpm}$ for $10 \mathrm{~min}$, and filtered through a $0.45 \mu \mathrm{m}$ pore size microfiltration membrane to remove unloaded drug. Drug-loaded micelles were lyophilized and kept at $4^{\circ} \mathrm{C}$ until further evaluations.

\section{Characterization of the micelles}

\section{Measurement of particle size and zeta potential}

The average hydrodynamic diameters and zeta potentials of the mixed micelle solutions $(1 \mathrm{mg} / \mathrm{mL})$ in phosphate buffer saline (PBS, $\mathrm{pH}$ 7.4) were measured with dynamic light scattering (DLS) using a ZetaSizer (3000HS, Malvern Instruments Ltd., Malvern, UK).

As outlined in the next section, the micelles were spray-dried with lactose to produce respirable micron size particles with a narrow particle distribution. Therefore, micelle size was also determined after spray drying of the micelles with lactose. A $50 \mathrm{mg}$ aliquot of the micelles embedded in lactose powder was dissolved in $4 \mathrm{~mL}$ of distilled water and the particle size was determined directly 
without any further dilution. All measurements were carried out at $25^{\circ} \mathrm{C}$ and performed in triplicate.

\section{Determination of critical micelle concentrations}

Critical micelle concentration (CMC) was determined by a fluorescence probe technique using pyrene as a fluorescence probe [21]. Briefly, 2 $\mathrm{mg} / \mathrm{mL}$ of the polymer mixtures at different molar ratios were prepared in DCM. Different volumes of these solutions were added to $15-\mathrm{mL}$ empty vials. Then $1 \mathrm{~mL}$ of $6 \times 10^{-6} \mathrm{M}$ solution of pyrene in DCM was added in every vial and mixed well. The DCM was left to evaporate for $24 \mathrm{~h}$ in order to form a pyrene film in the vials. Finally, $10 \mathrm{~mL}$ deionized water was added to the vials to obtain a final pyrene concentration of $6 \times 10^{-7} \mathrm{M}$ and the polymer solutions with concentrations ranging from $0.001 \mathrm{mg} / \mathrm{mL}$ to 1 $\mathrm{mg} / \mathrm{mL}$ at different weight ratios. The solutions were kept on a shaker at $37{ }^{\circ} \mathrm{C}$ for $24 \mathrm{~h}$ to reach equilibrium before fluorescence measurement. Fluorescence spectra were recorded using a spectrofluorometer (Jasco FP 750, Tokyo, Japan) with the excitation wavelength at $336 \mathrm{~nm}$. From the pyrene emission spectra, the intensity ratio of the first peak $\left(\mathrm{I}_{1}, 388 \mathrm{~nm}\right)$ to the third peak $\left(\mathrm{I}_{3}, 391 \mathrm{~nm}\right)$ was plotted against the logarithm of polymer concentrations. Two tangents were then drawn and the CMC values were taken from the intersection between the two tangents.

\section{Determination of drug loading}

Two mg of the lyophilized sample was dissolved in $25 \mathrm{~mL}$ of acetonitrile and the solution was ultrasonicated for $10 \mathrm{~min}$ to entirely dissolve PTXloaded micelles. The resultant solution was filtered through $0.45 \mu \mathrm{m}$ filter unit and PTX concentration was determined by HPLC method developed and validated in our laboratory [25]. Chromatographic separation was performed using a reversed-phase $\mathrm{C}_{18}$ - $\mu$ Bondapak $(3.9 \mathrm{~mm} \times 250 \mathrm{~mm}$ ) HPLC column . The mobile phase consisted of potassium dihydrogen phosphate $(0.01 \mathrm{M})$ /acetonitrile $(52: 48)$ with final $\mathrm{pH}$ adjusted to $4 \pm 0.1$ with orthophosphoric acid. The mobile phase eluted at $1.5 \mathrm{~mL} / \mathrm{min}$ and the effluent was monitored at $227 \mathrm{~nm}$ using a UV detector. Column temperature was kept at $40^{\circ} \mathrm{C}$ and $30 \mu \mathrm{L}$ of the sample was injected into the HPLC column. The calibration curve constructed in the range of $2.5-12 \mu \mathrm{g} / \mathrm{mL}$ of PTX was linear $\left(\mathrm{r}^{2}>\right.$ $0.998)$. The inter- and intra-day precision and accuracy of the assay were less than $10 \%$. Drug entrapment efficiency (EE) and drug loading (DL) were calculated by following equations:

$$
\begin{aligned}
& E E \%=\frac{\text { weight of the drug in the micelles }}{\text { weight of the feeding drug }} \times 100 \\
& D L \%=\frac{\text { weight of the drug in the micelles }}{\text { weight of the micelles }} \times 100
\end{aligned}
$$

\section{Drug release studies}

The lyophilized powder of PTX-loaded micelles (2 $\mathrm{mg}$ ) was dissolved in $2 \mathrm{~mL}$ of phosphate buffer solution ( $0.1 \mathrm{M}, \mathrm{pH}$ 7.4). The resulting solution was placed in a dialysis bag (MWCO: $10 \mathrm{kDa}$ ) which was immersed in a glass beaker with $100 \mathrm{~mL}$ phosphate buffer (0.1 M, pH: 7.4$)$ containing $0.2 \%$ tween 80 to provide sink condition with agitation of $100 \mathrm{rpm}$ at $37^{\circ} \mathrm{C}$ [21] . Sample aliquots were withdrawn from the release medium at pre-determined time intervals and replaced with fresh buffer. The content of PTX was determined by the above described HPLC method. Dissolution efficiency (DE) was used to compare the release rates amongst formulations. DE of release profiles were calculated from the area under the curve at time $\mathrm{tj}$ (measured using the trapezoidal rule) and expressed as the percentage of the area of the rectangle described by $100 \%$ dissolution in the same time [21]

\section{Cell culture}

Human lung cancer cells, A549, were maintained in DMEM/F12 supplemented with $10 \%$ (v/v) FBS and $1 \%$ penicillin-streptomycin at $37{ }^{\circ} \mathrm{C}$ and $5 \% \mathrm{CO} 2$. Cells were subcultured regularly using trypsin/EDTA.

\section{Cytotoxicity assay}

The cytotoxicities of the free drug in DMSO, PTXloaded $\quad$ TPGS $_{5 \mathrm{~K}} / \mathrm{TPGS}_{1 \mathrm{~K}} \quad(\underline{7}: 3), \quad$ blank ${\underline{\mathrm{TPGS}_{5 \mathrm{~K}}}} / \mathrm{TPGS}_{1 \mathrm{~K}} \quad(\underline{7}: 3), \mathrm{TPGS}_{5 \mathrm{~K}}$ micelles and Stragen ${ }^{\circledR}$ were assessed against A549 cell line using MTT assay. The cells were seeded at density of $7 \times$ $10^{4}$ cell $\mathrm{s} / \mathrm{mL}$ in a 96-well culture plate (SPL Lifescience, Gyeonggi-Do, Korea), and following an overnight cultivation for the cells to be attached to the wells, the cells were treated with samples for 72 $h$ at the equivalent PTX concentrations of 0.03-3 $\mu \mathrm{g} / \mathrm{mL}$.

After incubation, $20 \mu \mathrm{L}$ of MTT solution (5 $\mathrm{mg} / \mathrm{mL}$ in $0.02 \mathrm{M}$ phosphate buffer) was added to each well and the plate was incubated for another 4 h. Subsequently, unreacted MTT and medium was removed and the formazan crystals in cells were dissolved in $150 \mu \mathrm{L}$ of DMSO. The absorbance was 
measured at $570 \mathrm{~nm}$ using enzyme-linked immunosorbent assay plate reader (Stat Fax-2100; Awareness Technology Inc., Palm City, FL). Untreated cells were taken as the negative control with $100 \%$ viability and the blank culture medium was used as a blank control [25]. Cell viability for each sample was calculated using following equation.

$$
\text { Cell viability } \%=\frac{\text { mean absorbance of each group }- \text { mean absorbance of blank }}{\text { mean absorbance of negative control }- \text { mean absorbance of blank }} \times 100
$$

\section{Spray drying procedure}

Five grams of lactose was dissolved in $75 \mathrm{~mL}$ of distilled water and heated up to $40{ }^{\circ} \mathrm{C}$ to completely solubilize the lactose. Then the solution was mixed with $25 \mathrm{~mL}$ of colloidal solution of PTX-loaded micelles equivalent to $10 \mathrm{mg}$ of PTX. The dispersion was spray dried using a Buchi mini spray dryer B290 (Flawil, Switzerland) with pneumatic atomizer through a $1.4 \mathrm{~mm}$ nozzle. The spray drying was performed using pump flow rate of $2 \mathrm{~mL} / \mathrm{min}, 85 \%$ aspiration, inlet temperature of $50 \pm 5{ }^{\circ} \mathrm{C}$ with an outlet temperature of $60-65{ }^{\circ} \mathrm{C}$ [26]. The resultant powder was blown through the cyclone separator and collected in a container. Exhaust air extracted out of the cyclone by a vacuum pump and filtered through a fiber filter.

\section{The process yield and drug content uniformity of the spray dried powders}

The spray-drying process yield was calculated by gravimetric method, comparing the initial total solids amount with the resultant powder amount after spray drying as follows [27]:

$$
\text { process yield } \%=\frac{\text { weight of resultant powder }}{\text { total solid (lactose }+ \text { PTX }- \text { loaded micelles) }} \times 100
$$

In order to study drug content uniformity in the spray dried samples, $5 \mathrm{~mL}$ of acetonitrile was added to 5 $\mathrm{mg}$ of spray dried powder and the suspension was sonicated for $10 \mathrm{~min}$ using a bath sonicator to dissolve PTX. The resultant solution was filtered through $0.45 \mu \mathrm{m}$ filter unit and PTX concentration was determined by the HPLC method. The experiment was performed on three spray-dried samples.

\section{Scanning electron microscopic analysis}

Surface morphology of the lactose-micellar particles was examined using a scanning electron microscope (SEM; Hitachi, S-2400, Japan). The microparticles were vacuum dried, coated with gold palladium and observed microscopically.

\section{Deposition studies spray-dried powder}

The powders were aerosolized using a dry powder inhalation device (spinhaler). The in vitro deposition of the aerosolized drug was investigated using Andersen cascade impactor (ACI, Thermo Andersen,
Smyrna, GA). A total of $10 \mathrm{mg}$ of each spraydried powder was loaded into hard gelatin capsules (size 3). An air stream of $60 \mathrm{~L} / \mathrm{min}$ was produced throughout the system by attaching the outlet of the using ACI to a vacuum pump for $4 \mathrm{~s}$. The powder deposited in stages 0 to 7 , the mouthpiece and the stages were collected and the drug content in each stage was extracted by acetonitrile. The drug contents were then determined using HPLC method. From drug deposition data, the fine particle fraction $\left(\mathrm{FPF}_{\mathrm{ED}}<5.5 \mu \mathrm{m}\right)$, mass median aerodynamic diameter (MMAD), and percentage of emitted dose (ED\%) were calculated. FPF is defined as the fraction of the total dose of the powder less than or equal to an effective cut-off aerodynamic diameter of $5.5 \mu \mathrm{m}$ which is calculated by dividing the powder mass recovered from stage 1-7 of the impactor by the total particle mass in the capsule. MMAD was calculated by linear interpolation of the cumulative mass distribution to obtain the particle size for which the cumulative mass under this size was 50\%. Emitted dose was calculated as follow:

$$
E D=\frac{\text { initial mass in capsule }- \text { final mass remainig in capsule }}{\text { initial mass in capsule }} \times 100
$$




\section{STATISTICAL ANALYSIS}

Data are expressed as means of three separate experiments and were compared by independent sample t-test for two groups, and one-way ANOVA following LSD Post Hoc test for multiple groups. A $p$-value $<0.05$ was considered statistically significant in all cases. All statistical analyses were performed using SPSS 17.

\section{RESULTS}

\section{Synthesis of TPGS Fk $_{\mathbf{k}}$}

The formation of $\mathrm{TPGS}_{5 \mathrm{~K}}$ was confirmed by ${ }^{1} \mathrm{H}$ NMR and FT-IR spectra. As shown in Fig. 1, peaks around 0.86 and $1-1.5 \mathrm{ppm}$, which were attributed to the methyl and methylene protons of the long alkyl chain of $\alpha$-TS, are present in the spectrum of TPGS ${ }_{5 \mathrm{~K}}$ (Fig. 1c), while no such peaks exist at the same chemical shifts in the spectrum of MePEG (Fig. 1b). A strong signal around $3.5 \mathrm{ppm}$ in Fig. $1 \mathrm{~b}$ and Fig. $1 \mathrm{c}$ are assigned to hydrogens of the repeating units $\left(\mathrm{CH}_{2} \mathrm{CH}_{2} \mathrm{O}\right)$ of PEG. The hydrogens of methylene group of PEG adjacent to the hydroxyl group, $\mathrm{OH}-$ $\mathrm{C}_{2}-\mathrm{CH}_{2}-\mathrm{O}-\left(\mathrm{CH}_{2} \mathrm{CH}_{2} \mathrm{O}\right) \mathrm{n}$-, appeared at $3.77 \mathrm{ppm}$ in the spectrum of MePEG which shifted to $3.73 \mathrm{ppm}$ in the spectrum of TPGS indicating ester bond formation.

The coupling reaction between $\alpha$-TS and MePEG was further confirmed by FT-IR analysis. The FT-IR spectra of $\alpha$-TS, MePEG, and the final product are shown in Fig 2. In FT-IR spectrum of $\alpha$ TS (Fig. 2a), the absorption band around $1720 \mathrm{~cm}^{-1}$ related to the stretching vibration of the carbonyl group of succinyl disappeared in the spectrum of TPGS (Fig. 2c) and another band at $1752 \mathrm{~cm}^{-1}$ due to the $\mathrm{C}=\mathrm{O}$ stretching vibration of newly formed ester group is raised. MePEG (Fig. 2b) and TPGS $_{5 \mathrm{~K}}$ spectra had the same band at $1109 \mathrm{~cm}^{-1}$ which corresponded to the presence of C-O stretch of PEG. Furthermore, the absorption bands at 2931 and 2860 $\mathrm{cm}^{-1}$ representing asymmetric and symmetric stretching vibrations of the $\mathrm{CH}_{2}$ and $\mathrm{CH}_{3}$ of alkyl chain of $\alpha$-TS were observed in the spectrum of $\mathrm{TPGS}_{5 \mathrm{~K}}$. These observations confirm the formation of ester bond between the carboxyl group of $\alpha$-TS and the end hydroxyl group of MePEG.

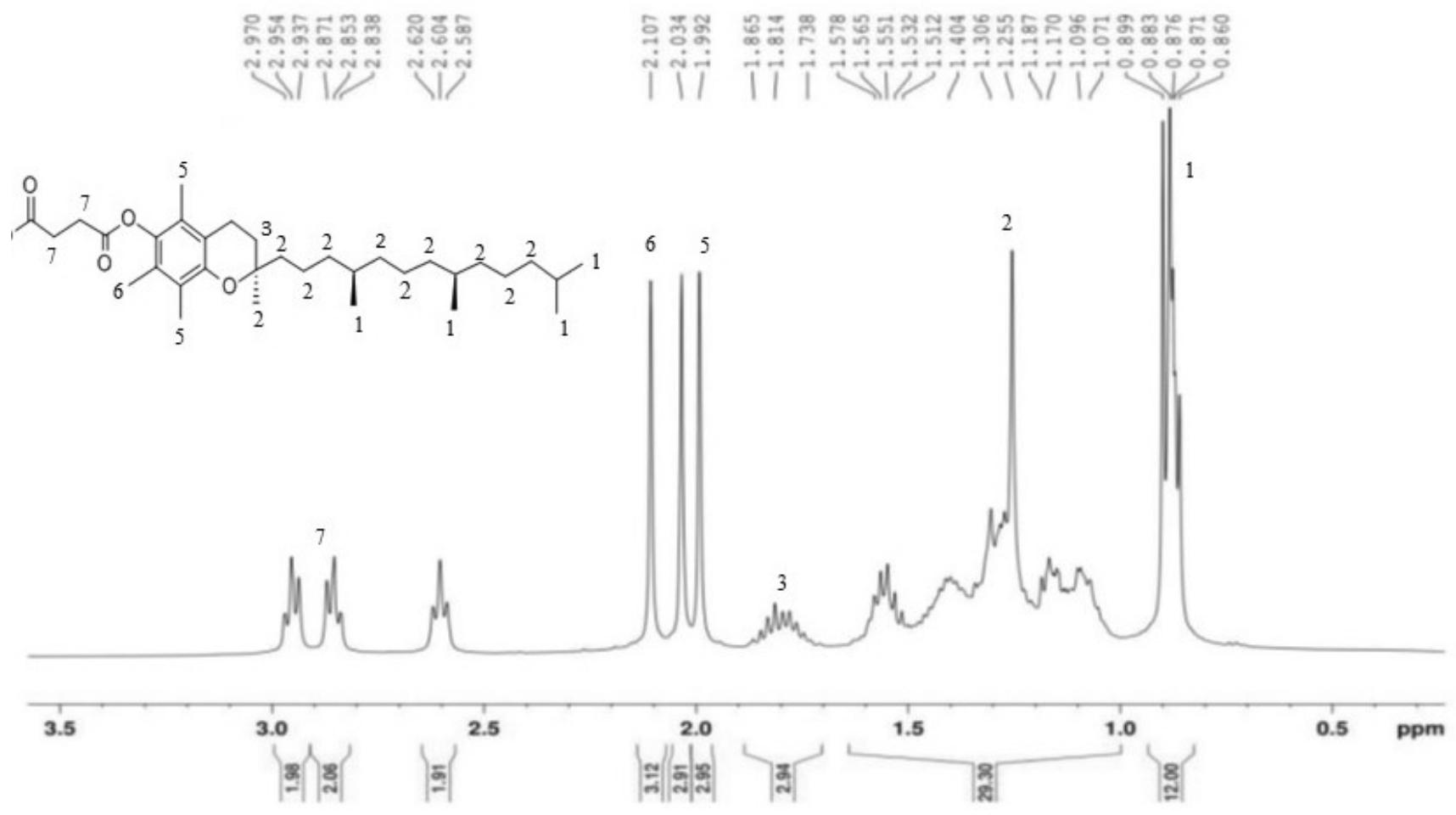




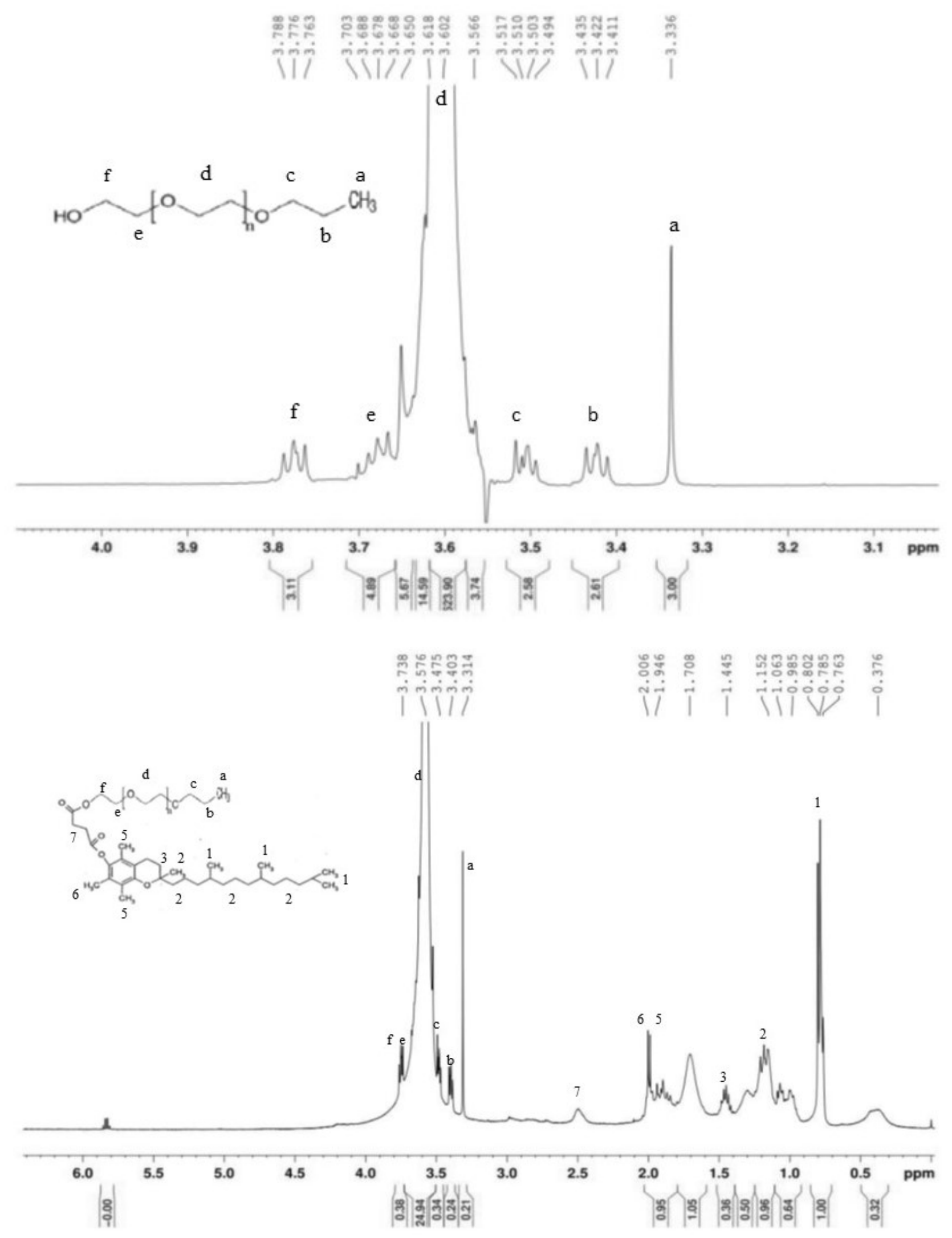

Figure 1. ${ }^{1} \mathrm{H}-\mathrm{NMR}$ spectra of (a) $\alpha$-TS in DMSO-d $\mathrm{d}_{6}$, (b) MePEG in $\mathrm{D}_{2} \mathrm{O}$, and (c) $\mathrm{TPGS}_{5 \mathrm{~K}}$ in $\mathrm{D}_{2} \mathrm{O}$. 


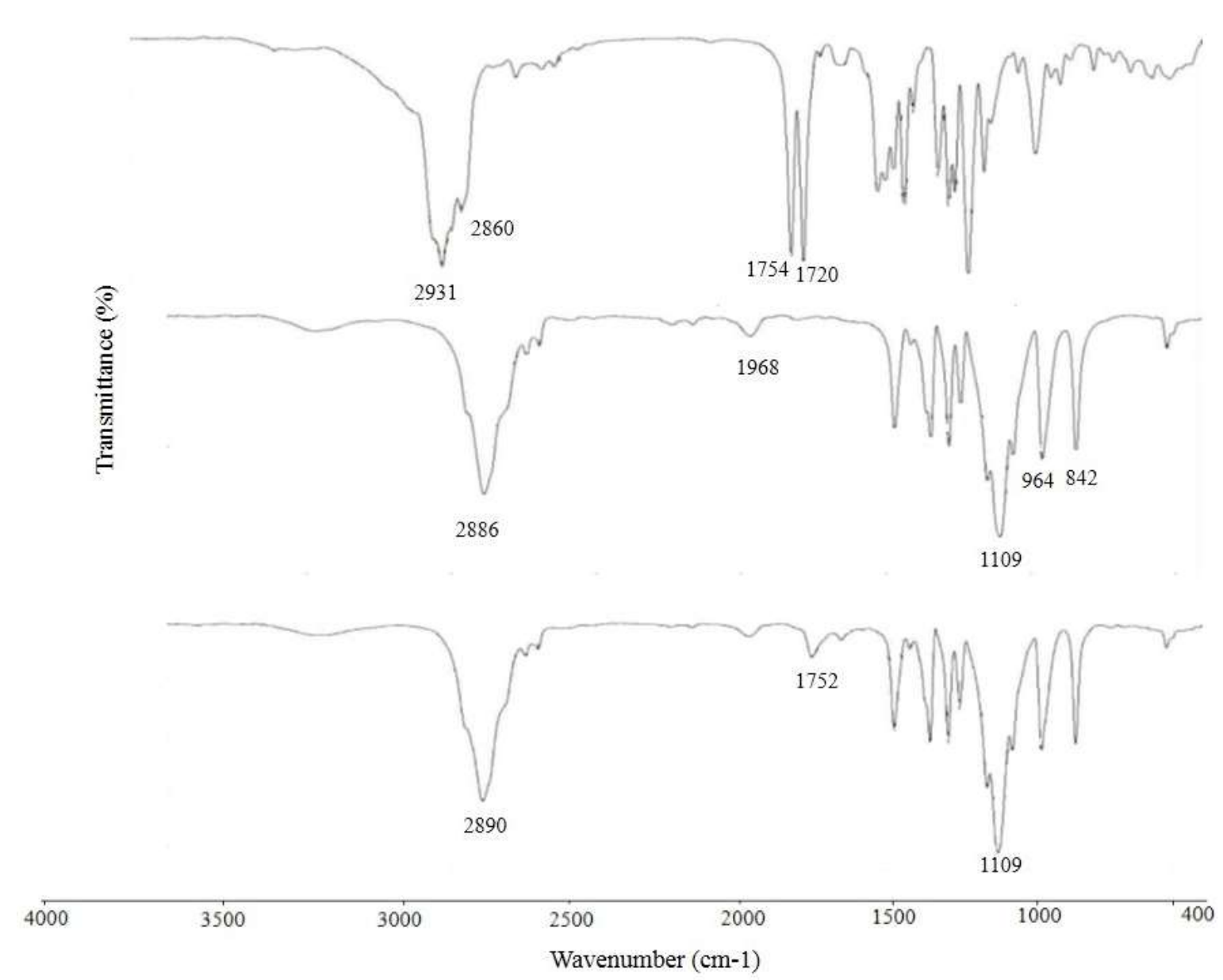

(a)

(b)

(c)

Figure 2. FT-IR spectra of (a) $\alpha-T S$, (b) MePEG, and (c) TPGS ${ }_{5 K}$.

\section{Characterization of blank and PTX-loaded micelles}

Fig. 3 shows the changes of fluorescence intensity ratios $\left(\mathrm{I}_{1} / \mathrm{I}_{3}\right)$ against the logarithm of $\mathrm{TPGS}_{5 \mathrm{~K}} / \mathrm{TPGS}_{1 \mathrm{~K}}$ in different molar ratios. The CMC of different mixtures in deionized water are also presented in Table 1. The CMC values decreased from $360 \mu \mathrm{M}$ for $\mathrm{TPGS}_{1 \mathrm{k}}$ to $8.4 \mu \mathrm{M}$ for $\mathrm{TPGS}_{5 \mathrm{~K}}$. As revealed, increasing the content of $\mathrm{TPGS}_{5 \mathrm{k}}$ in the mixtures has significantly decreased the CMC value of the micelles. The CMC values for $\mathrm{TPGS}_{5 \mathrm{~K}} / \mathrm{TPGS}_{1 \mathrm{~K}}(7: 3)$ and $\mathrm{TPGS}_{5 \mathrm{~K}} / \mathrm{TPGS}_{1 \mathrm{~K}}(5: 5)$ were found to be 17.89 and $16.33 \mu \mathrm{M}$, respectively, which are much lower than those of low molecular weight surfactants in water and indicate the micellar stability in biological environment. Table. 1 also listed the average sizes and zeta potentials of the lyophilized mixed micelles. The micellar sizes significantly increased from $102.6 \pm 7.2 \mathrm{~nm}$ for $\mathrm{TPGS}_{1 \mathrm{~K}}$ to $195.6 \pm 18.6 \mathrm{~nm}$ for $\mathrm{TPGS}_{5 \mathrm{~K}}$ micelles and the mixtures containing different quantity of $\mathrm{TPGS}_{5 \mathrm{k}}$ did not show significant changes in their sizes $(P>$ $0.05)$. The zeta potentials were varied from -13.8 to $-9.4 \mathrm{mV}$ and did not significantly change $(P>0.05)$ between different formulations. The EE varied from $30 \%$ to $41 \%$ in the different combinations. The loading capacity of the micelles prepared by $\mathrm{TPGS}_{1 \mathrm{~K}}$ alone was about $10 \%$ which reflected the low stability of $\mathrm{TPGS}_{1 \mathrm{~K}}$ micelles to incorporate the drug. In the current study, incorporation of $\mathrm{TPGS}_{5 \mathrm{~K}}$ as a part of micelle structure increased the EE to $40 \%$.

\section{In vitro drug release studies}

In vitro PTX release profiles from different micellar formulations and Stragen ${ }^{\circledR}$ are shown in Fig. 4. The release rates of PTX from the milcellar formulations were very slow and between $30-40 \%$ of the loaded drug was released after $72 \mathrm{~h}$. In comparison, PTX was rapidly released from Stragen ${ }^{\circledR}$ and $70 \%$ of the drug was released during $48 \mathrm{~h}$. the DE\% 072 for 10:0, 
7:3, and 5:5 micellar combinations were calculated $22.25 \% \pm 3.7,24.93 \% \pm 2.2$, and $19.73 \% \pm 2.3$ respectively and significant differences were not observed $(P>0.05)$. While, the DE\% ${ }_{72}$ of Stragen ${ }^{\circledR}$ $(58.87 \% \pm 7.2)$ was significantly greater $(\mathrm{P}<0.05)$ than micellar formulations indicating the slower drug release pattern.

\section{In vitro cytotoxicity studies}

Fig. 5 compares cytotoxic effects of free PTX in DMSO, Stragen ${ }^{\circledR}$, blank, and the drug-loaded micelles against A549 cells. Stragen ${ }^{\circledR}$ and free PTX showed similar cytotoxicity in the range of 0.03 to $1.5 \mu \mathrm{g} / \mathrm{mL}$ of PTX concentrations. However, the cytotoxicity of the free drug did not significantly change in concentrations higher than $1 \mu \mathrm{g} / \mathrm{mL}$ which might be attributed to the precipitation of the drug at high concentrations. The higher cytotoxic effect ( $p<$ $0.05)$ of Stragen ${ }^{\circledR}$ compared to the free drug at concentrations of 2 and $3 \mu \mathrm{g} / \mathrm{mL}$ could be due to the cytotoxicity of its vehicle, Cremophor ${ }^{\circledR}$ EL. PTXloaded mixed micelles exhibited the highest cytotoxicity among studied groups which was significant at concentrations higher than $1 \mu \mathrm{g} / \mathrm{mL}$. The empty micelles did not show any measurable toxicity at low concentrations $(<1 \mu \mathrm{g} / \mathrm{mL})$, however, the viability of the cells was significantly decreased to about $75 \%$ once the micelle concentrations increased which imply the cytotoxic effect of TPGS.

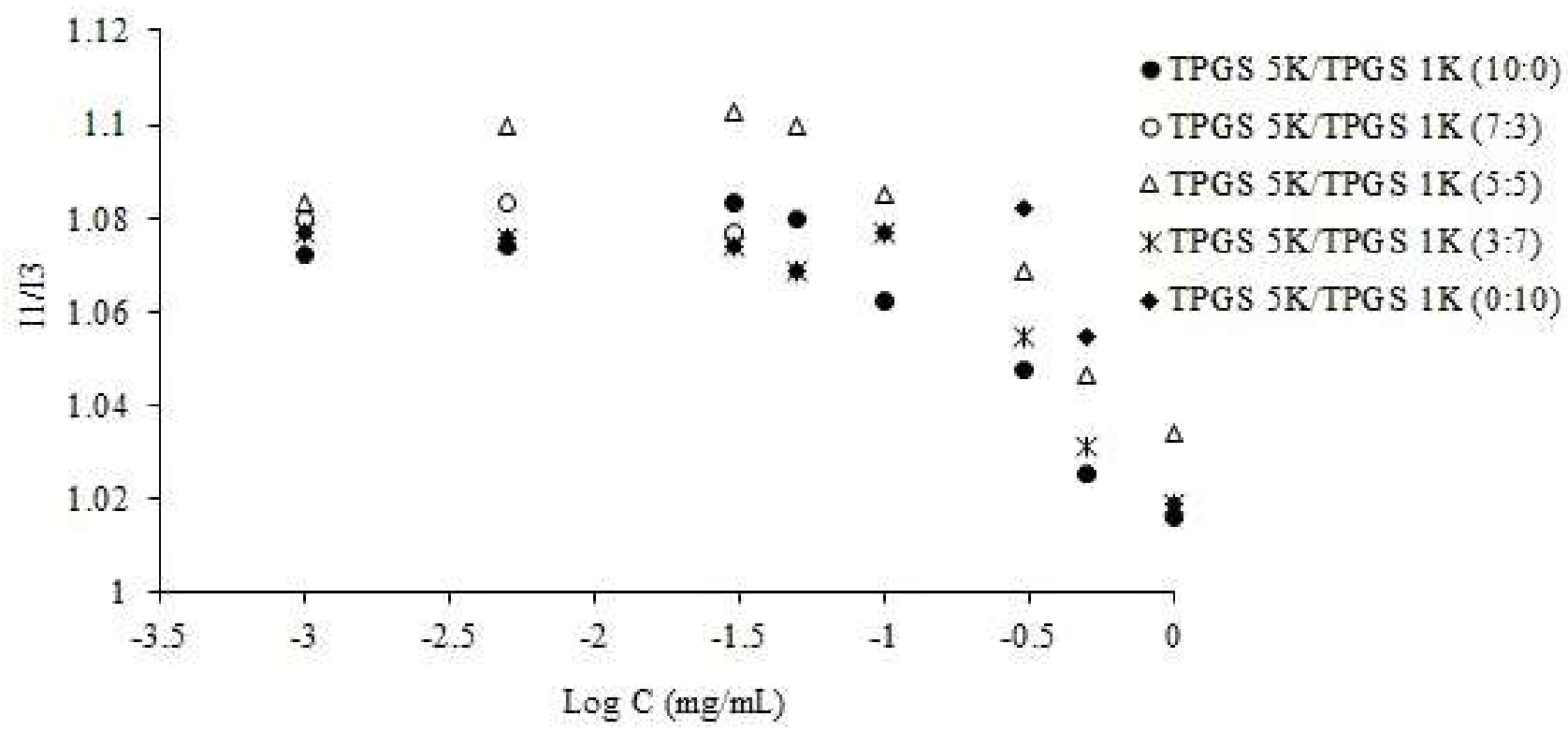

Figure 3. Fluorescence intensity variations of $\mathrm{I}_{1} / \mathrm{I}_{3}$ for pyrene emission against the logarithm of $\mathrm{TPGS}_{5 \mathrm{~K}} / \mathrm{TPGS}_{1 \mathrm{~K}}$ concentrations

Table 1. Characteristics of blank and drug-loaded $\mathrm{TPGS}_{5 \mathrm{~K}} / \mathrm{TPGS}_{1 \mathrm{~K}}$ mixed micelles.

\begin{tabular}{|c|c|c|c|}
\hline formulations & $\mathrm{CMC}(\mu \mathrm{M})$ & Micellar size (nm) & Zeta potential $(\mathrm{mV})$ \\
\hline $\mathrm{TPGS}_{\underline{5 K}} / \mathrm{TPGS}_{1 \mathrm{~K}}(\underline{10}: 0)$ & 8.4 & $195.6 \pm 18.6$ & $-13.8 \pm 1.6$ \\
\hline$\overline{\mathrm{TPGS}_{5 K}} / \mathrm{TPGS}_{1 \mathrm{~K}}(\overline{\mathrm{7}: 3})$ & 17.89 & $175.1 \pm 19.2$ & $-12.7 \pm 1.9$ \\
\hline $\mathrm{TPGS}_{5 \mathrm{~K}} / \mathrm{TPGS}_{1 \mathrm{~K}}(\underline{5}: 5)$ & 16.33 & $145.2 \pm 12.3^{*}$ & $-11.9 \pm 2.1$ \\
\hline $\mathrm{TPGS}_{\underline{5 K}} / \mathrm{TPGS}_{1 \mathrm{~K}}(\underline{3}: 7)$ & 65 & $115.8 \pm 9.5^{*}$ & $-10.6 \pm 0.8$ \\
\hline \multirow{2}{*}{$\underline{\mathrm{TPGS}_{5 K}} / \mathrm{TPGS}_{1 \mathrm{~K}}(\underline{0}: 10)$} & 360 & $102.6 \pm 7.2^{*}$ & $-9.4 \pm 1.2$ \\
\hline & $\mathrm{EE} \%(\mathrm{DL} \%)$ & Micellar size (nm) & Zeta potential $(\mathrm{mV})$ \\
\hline PTX/TPGS ${ }_{5 K} /$ TPGS $_{1 \mathrm{~K}}(\underline{10}: 0)$ & $41.22 \pm 5.3(11.8 \pm 1.4)$ & $255.2 \pm 21.2$ & $-7.86 \pm 1.1$ \\
\hline PTX/TPGS $\underline{5 K} /$ TPGS $_{1 \mathrm{~K}}(\underline{7}: 3)$ & $41.36 \pm 6.1(12.4 \pm 1.6)$ & $244 \pm 19.5$ & $-7.68 \pm 0.8$ \\
\hline $\mathrm{PTX}^{\mathrm{TPGS}} \underline{\underline{5 K}}_{\underline{\mathrm{TPGS}}} / \mathrm{TP}_{1 \mathrm{~K}}(\overline{5}: 5)$ & $37.7 \pm 3.9(11.3 \pm 1.1)$ & $261.9 \pm 26.3$ & $-7.62 \pm 0.9$ \\
\hline PTX/TPGS ${ }_{\underline{5 K}} /$TPGS $_{1 \mathrm{~K}}(\underline{3}: 7)$ & $30.9 \pm 2.8(9.27 \pm 0.94)^{*}$ & $222.8 \pm 25.1^{*}$ & $-5.19 \pm 0.8$ \\
\hline PTX/TPGS $/ \overline{T P K}_{5 \mathrm{TPS}} / \mathrm{TP}_{1 \mathrm{~K}}(\mathbf{0}: 10)$ & $10.1 \pm 1.1(2.2 \pm 0.2)^{*}$ & $118.6 \pm 12.5^{*}$ & $-5.3 \pm 0.5$ \\
\hline $\begin{array}{l}\text { EE: entrapment efficiency } \\
\text { DL: drug loading } \\
* \mathrm{P} \text { value } \leq 0.05 \text { compared to }\end{array}$ & $\underline{\underline{S}}_{1 \mathrm{~K}}(10: \underline{0})$ & & \\
\hline
\end{tabular}




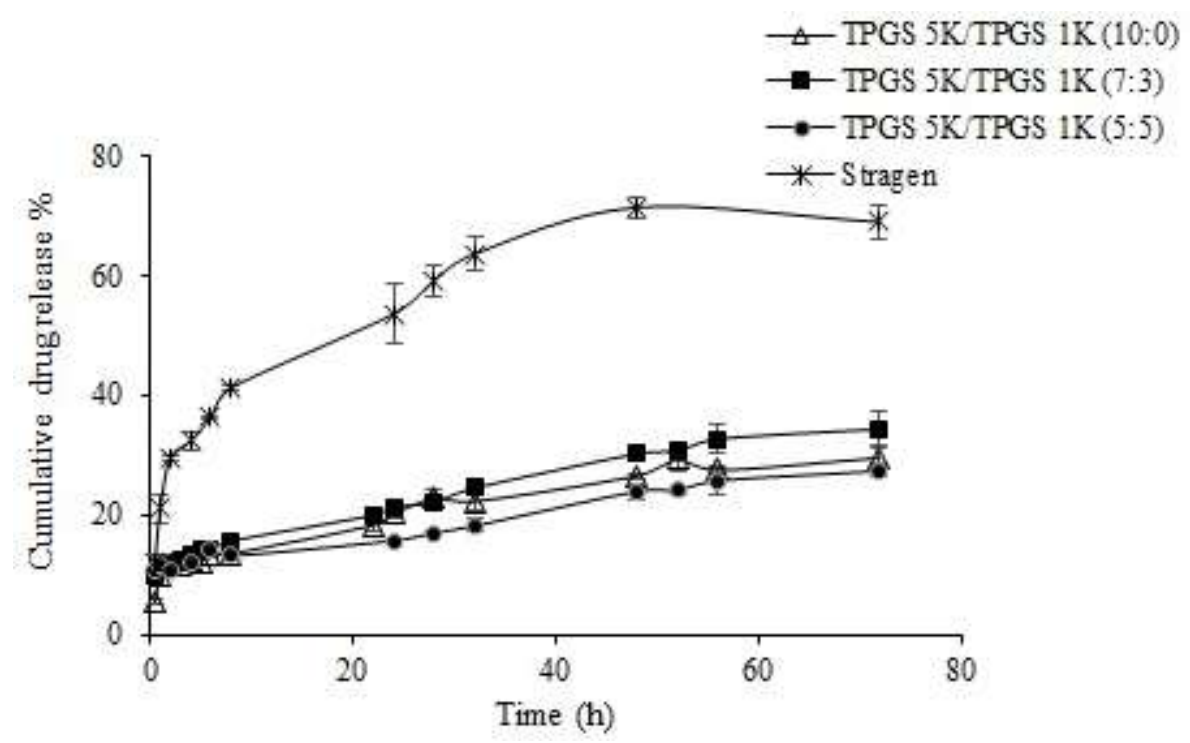

Figure 4. In vitro drug-release profiles from Stragen ${ }^{\circledR}$ and the mixed micelles with different molar ratios of the structural composition. Data represent the mean \pm standard deviation $(n=3)$.

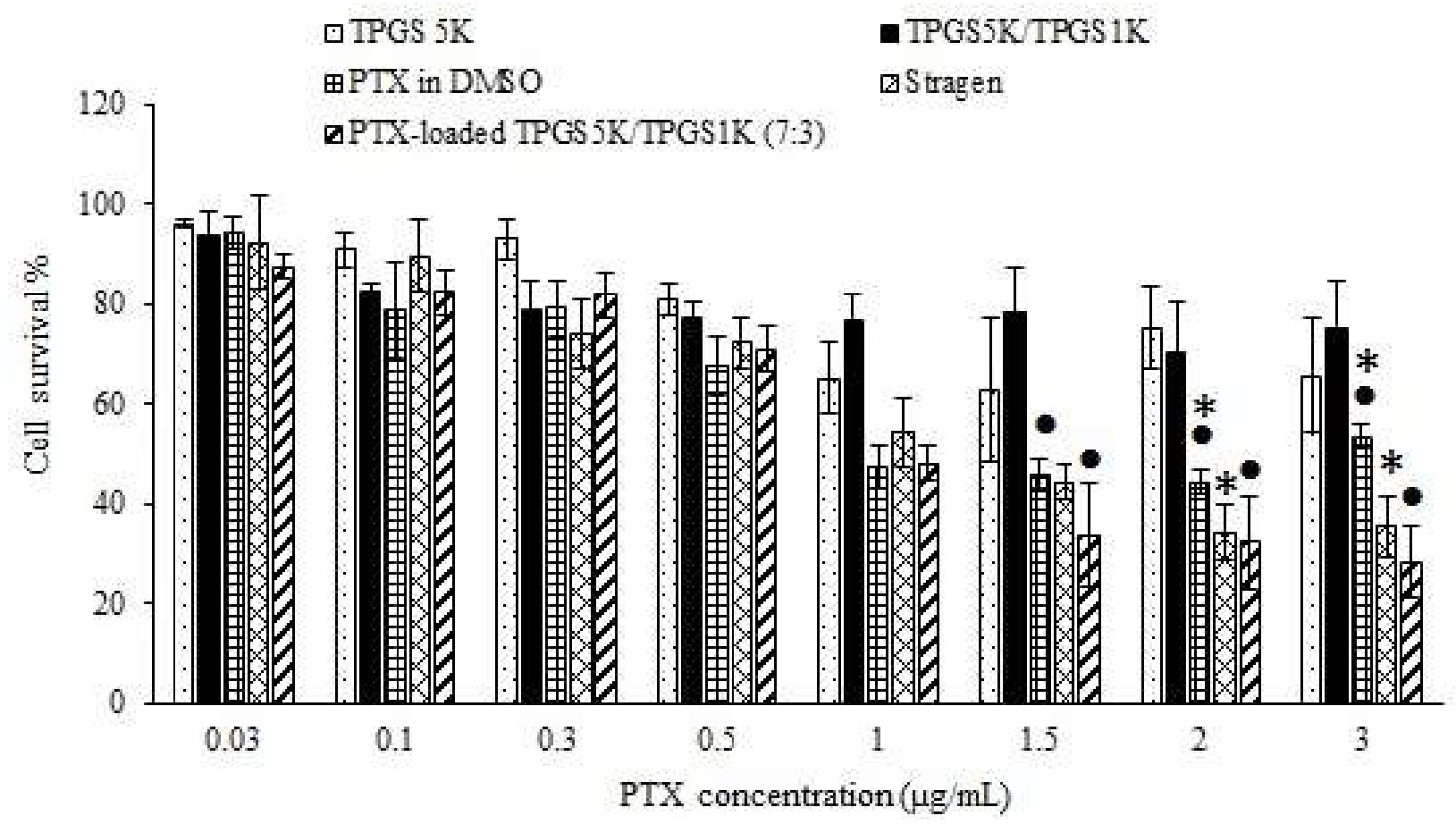

Figure 5. In vitro cytotoxic activities of various PTX formulations and blank micelles against A549 cell line after $72 \mathrm{~h}$ incubation. Data are plotted as the mean \pm standard deviation $(\mathrm{n}=3){ }^{*} \cdot \mathrm{P}<0.05 *$ Higher cytotoxic effect $(p<0.05)$ of Stragen ${ }^{\circledR}$ compared to the free drug at concentrations of 2 and $3 \mu \mathrm{g} / \mathrm{mL} \cdot$ Significant greater cytotoxicity of PTX-loaded TPGS5K/TPGS1K micelles compared to the free drug at concentrations higher than $1 \mu \mathrm{g} / \mathrm{mL}$

\section{Characterization of spray-dried powders}

The mean particle sizes of the drug-loaded micelles were measured before spray-drying and after re- dissolving of the spray-dried powders. The mean particle sizes of the micelles increased from $250 \mathrm{~nm}$ to $310 \mathrm{~nm}$ during spray drying procedure. Although after spray-drying the size of the micelles were 
significantly increased, they were still in the nanorange sizes. The percentages of content uniformity for powders were between $95-105 \%$ and the process yields was calculated about $30-45 \%$.

\section{Size and morphology of PTX-loaded embedded in lactose microparticles}

The particle dimensions and surface morphology of the spray-dried powders were visualized using scanning electron microscopy (Fig. 6). Spray-dried lactose particles containing PTX-loaded micelles were perfectly spherical with a smooth surface. The mean geometric particle size of spray-dried powders was $2.5 \mu \mathrm{m}$, within the respirable particle size range ideal for maximizing pulmonary deposition of dry powders.

\section{In vitro deposition studies using ACI}

Fig. 7 shows the percent of drug deposited on various stages of ACI. Each bar represents the powder of certain sizes collected on a defined stage of the ACI. The fraction of all particles smaller than $5.5 \mu \mathrm{m}$ represents the inhalable $\mathrm{FPF}_{\mathrm{ED}<5.6 \mu \mathrm{m}}$. The percentage of $\mathrm{FPF}_{\mathrm{ED}<5.6 \mu \mathrm{m}}$ and $\mathrm{ED} \%$ were $60.1 \% \pm 10.23$ and $89.8 \% \pm 4$, respectively. The MMAD of pure lactose and PTX-loaded micelles embedded in lactose were
$3.2 \pm 0.52$ and $3.8 \pm 0.98 \mu \mathrm{m}$, respectively. A $t$-test analysis showed that the incorporation of nanoparticles into lactose by spray-drying had no significant effect on the fine particle fraction and MMAD of the powders.

\section{DISCUSSION}

Pulmonary delivery of drugs to treat respiratory diseases offers several advantages such as rapid onset of therapeutic action, high drug concentration within the lung, and minimum systemic side effects [28]. In addition, many drugs delivered via intravenous or oral route often result in high systemic concentrations of drugs while relatively low amount of drugs in the lung. Specifically, for lung cancer, pharmacokinetic data has demonstrated low drug concentrations in the lung after systemic administration, which could consequently cause the failure of treatment and development of the high proportion of chemotherapeutic drug resistant cancer cells. Nebulizers, pressurized metered dose inhalers (PMDI), and dry powder inhalers (DPI) are the various types of pulmonary drug delivery systems which are commercially used for the treatment of lung disorders.

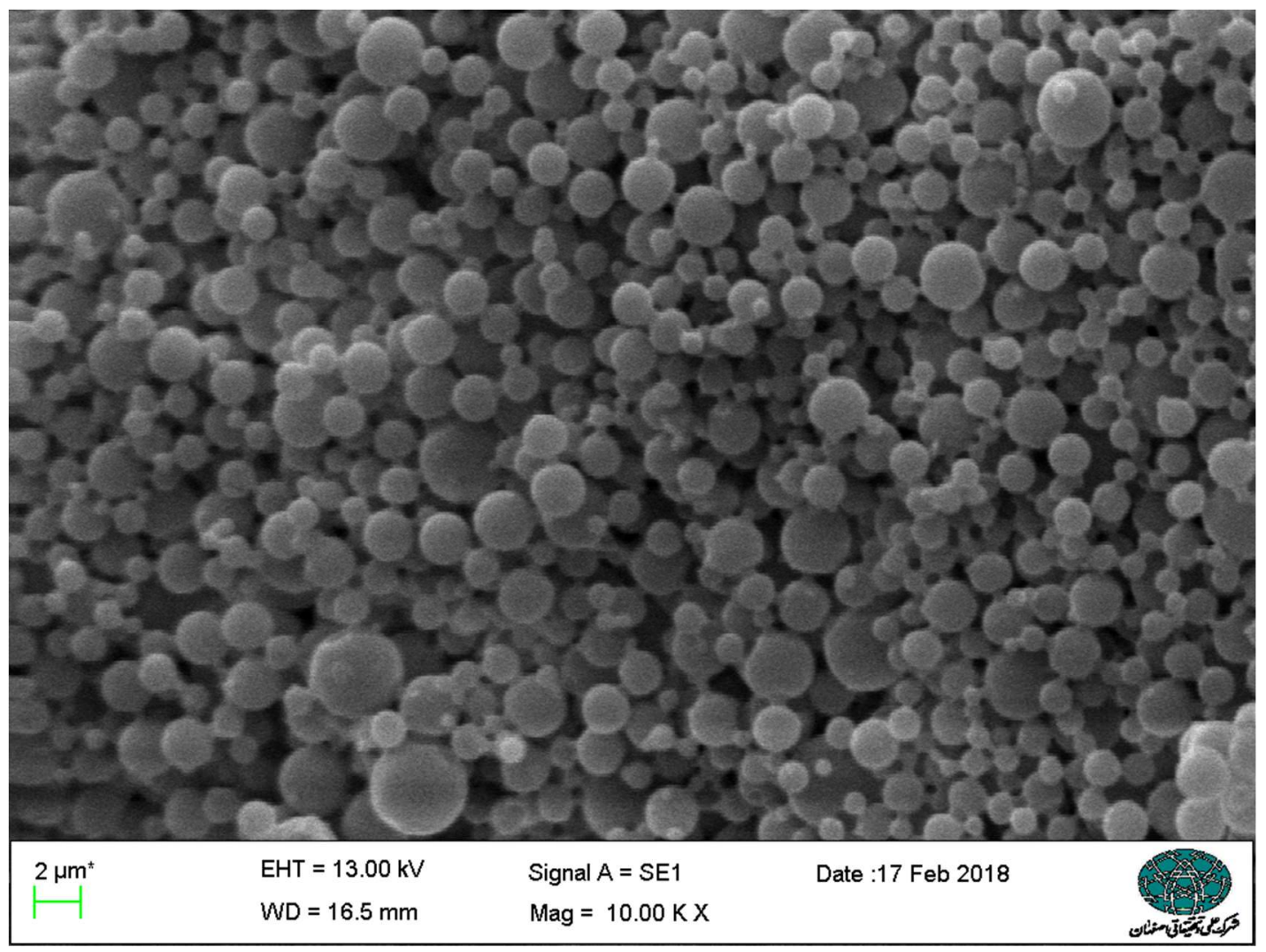

Figure 6. Spray-dried powder morphology visualized by scanning electron microscopy 


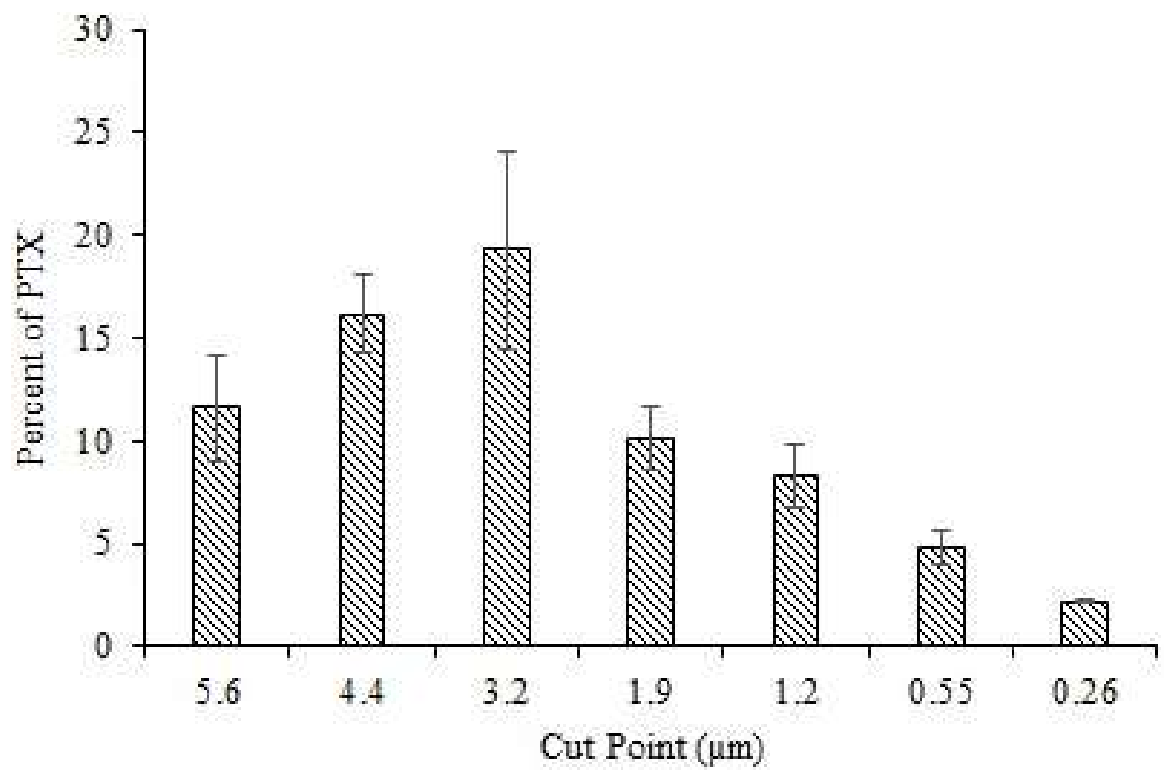

Figure 7. Drug deposition patterns of spray-dried PTX-loaded micelles embedded in lactose powder in the cascade impactor.

Nebulizers and PMDI are liquid-based aerosols while DPI are in a solid form. DPI offers some advantages compared to other types of pulmonary delivery systems [29]. This includes designing appropriate particle size and exact amount of drug loaded into the system, improving chemical stability relative to liquid aerosols and long-term stability during storage and ease of use for patients. Because of the local toxicity of anticancer agents they cannot be directly aerosolized. In this study, PTX was entrapped in polymeric micelles and then incorporated into lactose microparticles as a DPI pulmonary delivery system for lung cancer. Polymeric micelles have a core-shell structure where lipophilic drugs can be solubilized in the cores of micelles. Here we fabricated micelles with the mixture of $\mathrm{TPGS}_{1 \mathrm{~K}}$ and $\mathrm{TPGS}_{5 \mathrm{~K}}$ at different molar ratios to achieve the optimized formulation with the lowest $\mathrm{CMC}$ values and the highest drug loading. Despite the unique advantages of TPGS $_{1 \mathrm{k}}$ such as anticancer activity and inhibition of p-gp, it has a high $\mathrm{CMC}$ value $(360 \mu \mathrm{M})$, which decreases the stability of micelles in physiological environment. Collnot et al [30] synthesized a homologous group of TPGS analogs which varied in PEG chain length (TPGS 200, 238, 400, 600, 1000, 2000, 3400, 3500 4000, and 6000) and evaluated the effect of PEG chain length on inhibition of p-gp efflux pump. The results revealed that commercial TPGS $_{1 \mathrm{~K}}$ was the most potent analogs in inhibition of p-gp. Thus in the current study, the micelles were formulated from $\mathrm{TPGS}_{1 \mathrm{~K}}$ and $\mathrm{TPGS}_{5 \mathrm{~K}}$ in different molar ratios to improve the stability of the micelles and achieve higher cytotoxic effect.. TPGS ${ }_{5 \mathrm{~K}}$ was synthesized through the reaction of $\alpha$-TS with MePEG 5kDa with much lower CMC value $(8.4 \mu \mathrm{M})$ compared to $\mathrm{TPGS}_{1 \mathrm{~K}}$ alone. In agreement with our results, $\mathrm{Mi}$ and co-workers synthesized $\mathrm{TPGS}_{2 \mathrm{~K}}$ which was conjugated to folic acid for targeted delivery of docetaxel [31]. The CMC value of $\mathrm{TPGS}_{2 \mathrm{~K}}$ was significantly much lower than that of $\mathrm{TPGS}_{1 \mathrm{~K}}$. In another study the effects of degree of substitution and molecular weight of MePEG on CMC value of MePEG-conjugated octyl-chitosan micelles were evaluated [32]. The results revealed that by increasing the molecular weight of MePEG and its degree of substitution, the CMC value was significantly decreased.

As shown in Table 1, incorporation of $\mathrm{TPGS}_{5 \mathrm{~K}}$ as a part of micellar structure significantly increased the micellar size, which might result from the stretch of PEG 5kDa with long chains on the micelle surface toward water phase. In other studies, incorporation of PEG with long chain in micellar structure increased the size and decreased the zeta potentials of the nanoparticles $[25,33]$. As listed in Table 1, the size of PTX-loaded micelles was larger than those of the blank micelles which is attributed to the drug loaded in the micellar core. The reduction in zeta potential after the drug loading could be due to the 
change of size and surface charge density of the micelles. In our previous studies using polymeric micelles for delivery of PTX, loading the drug in the core of micelles increased the size and decreased the zeta potentials of the micelles [21, 25, 34].

The sustained release behaviors observed in all of the formulations could be explained by high solubility of PTX in the micelles' core and the strong hydrophobic interactions between PTX and the bulk lipophilic portion of TPGS molecules that prevent the drug release in the medium. In other published studies, $\alpha$-TS as a part of micelle formation decreased the drug release rate which is in accordance with our results $[21,22,33]$. The cytotoxic effects of different formulation was evaluated against human lung cancer cells and demonstrated the highest cytotoxicity for the micellar formulation. The increased cytotoxicity of PTX-loaded micelles could be explained by solubilization of PTX in the core of micelles and unique apoptosis-inducing properties of TPGS. . Recent studies revealed that $\mathrm{TPGS}_{1 \mathrm{~K}}$ possesses potent antitumor activity even higher than that of $\alpha$ TS [34,35]. The cellular results indicated that antitumor effects of $\mathrm{TPGS}_{1 \mathrm{~K}}$ is due to its ability to induce reactive oxygen species (ROS) generation and apoptosis [35]. In addition, TPGS $_{1 \mathrm{~K}}$ through the inhibition of drug efflux pumps or P-gps, could facilitate delivery of PTX to the site of action, which is located in the nucleus. Recently, we developed a novel mixed polymeric micelles containing $\mathrm{TPGS}_{1 \mathrm{~K}}$ for co-delivery of PTX and retinoic acid to the cancer cells [21]. The results of cell culture studies on human breast cancer cells, MCF-7, demonstrated the cytotoxic effect of $\mathrm{TPGS}_{1 \mathrm{~K}}$. The decrease in cell viability for the empty micelles at higher concentrations also implies the cytotoxic effect of TPGS. Based on the physicochemical evaluation and cytotoxicity studies, the 7:3 micellar formulation was adopted as an optimized formulation. The micelles were spray-dried together with lactose carriers and produced powder particle diameters of several micrometers with a narrow particle distribution. Through MMAD and FPF obtained by ACI it could be predicted that maximum deposition of the embedded drugs in the trachea-bronchial and deep alveoli regions for normal inhalation rate. After deposition in the lung, the carrier matrix dissolves and releases the nanoparticles where the micelle sizes are still in the nano-size scale after spray drying indicating drug accumulation in cancer cells.

\section{CONCLUSION}

In the current study polymeric micelles containing PTX was peppered and further co-spray-dried with lactose carrier. The physicochemical characterization and excellent aerosol dispersion performance of these particles indicates that they would be suitable to deliver PTX to the middle and deep regions of the lungs. This study supports the approach of local lung cancer treatment using nanoparticles as a drug delivery vector. The development of inhalable nanoparticles loaded with bioactive molecules is a new delivery platform which can allow targeting of lung specific diseases in the future.

\section{REFERENCES}

1. Lee WH, Loo Ch, Traini D, Young PM. Inhalation of nanoparticle-based drug for lung cancer treatment: Advantages and challenges. Asian journal of pharmaceutical sciences, 2015; 10: 481-489.

2. Sung JC, Pulliam BL, Edwards DA. Nanoparticles for drug delivery to the lungs. Trends Biotechnol, 2007; 25: 563-570.

3. The Potential Advantages of Nanoparticle Drug Delivery Systems in Chemotherapy of Tuberculosis Gelperina S, Kisich K, Iseman MD., Heifets L. American J. Respiratory and Critical Care Medicine. 2005: 172:

4. Kanehira Y, Togami K, Tada H, Chono S. Tumor distribution and anti-tumor effect of doxorubicin following intrapulmonary administration to mice with metastatic lung tumor. J Drug Deliv Sci Technol, 2016; 33: 143-148.

5. Goel A, Baboota S, Sahni JK, Ali J. exploring targeted pulmonary delivery for treatment of lung cancer. Int J Pharm Investig, 2013; 3: 8-14.

6. Yang R, Yang SG, Shim WS, Cui F, Cheng G, Kim IW, et al. Lung-Specific Delivery of Paclitaxel by Chitosan-Modified PLGA Nanoparticles Via Transient Formation of Microaggregates. J Pharm Sci, 2009; 98: 970-984.

7. Taratula O, Kuzmov A, Shah M, Garbuzenko O, Minko T. Nanostructured lipid carriers as multifunctional nanomedicine platform for pulmonary co-delivery of anticancer drugs and siRNA. J Control Release, 2013; 171: 349-357.

8. Anabousi S, Bakowsky U, Schneider M, Huwer H, Lehr CM, Ehrhardt C. In vitro assessment of transferrin-conjugated liposomes as drug delivery systems for inhalation therapy of lung cancer. Eur J Pharm Sci, 2006; 29: 367-374.

9. Sham JO, Zhang Y, Finlay WH, Roa WH, Löbenberg R. Formulation and characterization of spray-dried 
powders containing nanoparticles for aerosol delivery to the lung. Int J Pharm, 2004; 269: 457-467

10. Azarmi S, Tao X, Chen H, Wang Z, Finlay WH, Löbenberg R, et al. Formulation and cytotoxicity of doxorubicin nanoparticles carried by dry powder aerosol particles. Int J Pharm, 2006; 319: 155-161.

11. Yang YT, Chen CT, Yang JC, Tsai T. Spray-dried microparticles containing polymeric micelles encapsulating hematoporphyrin. AAPS J, 2010; 12: 138-146.

12. Rao AK, Shrikhande Sh, Bajaj A. Development of Cisplatin Nanoparticles as Dry Powder Inhalers for Lung Cancer. Curr Nanosci, 2013; 9: 447-450.

13. Emami J, Rezazadeh M, Varshosaz J, Tabbakhian M, Aslani A. Formulation of LDL Targeted Nanostructured Lipid Carriers Loaded with Paclitaxel: A Detailed Study of Preparation, Freeze Drying Condition, and In Vitro Cytotoxicity. J Nanomater, 2012; 2012: 3258-3262.

14. Alipour Sh, Montaseri H, Tafaghodi M. Preparation and characterization of biodegradable paclitaxel loaded alginate microparticles for pulmonary delivery. Colloids Surf B Biointerfaces, 2010; 81: 521-529.

15. Taratula O, Kuzmov A, Shah M, Garbuzenko O, Minko T. Nanostructured lipid carriers as multifunctional nanomedicine platform for pulmonary co-delivery of anticancer drugs and siRNA. J Control Release, 2013; 171: 349-357.

16. Grenha A, Grainger CI, Dailey LA, Seijo B, Martin GP, Remuñán-López $\mathrm{C}$, et al. Chitosan nanoparticles are compatible with respiratory epithelial cells in vitro. Eur J Pharm Sci, 2007; 31:73-84.

17. Gill K, Nazzal S, Kaddoumi A. Paclitaxel loaded PEG5000-DSPE micelles as pulmonary delivery platform: Formulation characterization, tissue distribution, plasma pharmacokinetics, and toxicological evaluation. Eur J Pharm Biopharm, 2011; 79: 276-284.

18. Videira M, Almeida A, Fabra À. Preclinical evaluation of a pulmonary delivered paclitaxelloaded lipid nanocarrier antitumor effect. Nanomedicine, 2012; 8: 1208-1215.

19. Yang R1, Yang SG, Shim WS, Cui F, Cheng G, Kim IW, et al. Lung-Specific Delivery of Paclitaxel by Chitosan-Modified PLGA Nanoparticles Via Transient Formation of Microaggregates. J Pharm Sci, 2009; 98: 970-984.

20. Koshkina NV, Waldrep JC, Roberts LE, Golunski E, Melton S, Knight V. Paclitaxel Liposome Aerosol Treatment Induces Inhibition of Pulmonary Metastases in Murine Renal Carcinoma Model. Clin. Cancer Res, 2001; 7: 3258-3262.

21. Emami J, Rezazadeh M, Mashayekhi M, Rostami M, Jahanian-Najafabadi A. A novel mixed polymeric micelle for co-delivery of paclitaxel and retinoic acid and overcoming multidrug resistance: synthesis, characterization, cytotoxicity, and pharmacokinetic evaluation. Drug Dev Ind Pharm, 2018; 44: 729-740.

22. Zhu H, Chen H, Zeng X, Wang Z, Zhang X, Wu Y, et al. Co-delivery of chemotherapeutic drugs with vitamin E TPGS by porous PLGA nanoparticles for enhanced chemotherapy against multi-drug resistance. Biomaterials, 2014; 35: 2391-2400.

23. Xu P, Yin Q, Shen J, Chen L, Yu H, Zhang Z, et al. Synergistic inhibition of breast cancer metastasis by silibinin-loaded lipid nanoparticles containing TPGS. Int J Pharm, 2013; 454: 21-30.

24. Gill KK, Kaddoumi A, Nazzal S. Mixed micelles of PEG(2000)-DSPE and vitamin-E TPGS for concurrent delivery of paclitaxel and parthenolide: enhanced chemosenstization and antitumor efficacy against non-small cell lung cancer (NSCLC) cell lines. Eur J Pharm Sci, 2012; 46: 64-71.

25. Emami J, Rezazadeh M, Hasanzadeh F, Sadeghi H, Mostafavi A, Minaiyan M, et al. Development and in vitro/in vivo evaluation of a novel targeted polymeric micelle for delivery of paclitaxel. Int J Biol Macromol, 2015; 80: 29-40.

26. Sham JO, Zhang Y, Finlay WH, Roa WH, Löbenberg R. Formulation and characterization of spray-dried powders containing nanoparticles for aerosol delivery to the lung. Int J Pharm, 2004, 269: 457-467.

27. Pourshahab PS, Gilani K, Moazeni E, Eslahi H, Fazeli MR, Jamalifar H. Preparation and characterization of spray dried inhalable powders containing chitosan nanoparticles for pulmonary delivery of isoniazid. J Microencapsul, 2011; 28: 605-613.

28. Meenach SA, Anderson KW, Zach Hilt J, McGarry RC, Mansour HM. Characterization and aerosol dispersion performance of advanced spray-dried chemotherapeutic PEGylated phospholipid particles for dry powder inhalation delivery in lung cancer. Eur J Pharm Sci, 2013; 49: 699-711.

29. Islam N, Gladki E. Dry powder inhalers (DPIs) - A review of device reliability and innovation. Int. J. Pharmaceutics 2008: 360: 1-11

30. Collnot E, Baldes Ch, Wempe M, Hyatt J, Navarro L, Edgar K, Schaefer U, Lehr C. Influence of vitamin E TPGS poly(ethylene glycol) chain length on apical efflux transporters in Caco-2 cell monolayers. J. Control. Release 2006: 111: 35-40

31. Mi Y, Liu Y, Feng SS. Formulation of Docetaxel by folic acid-conjugated $\mathrm{d}$ - $\alpha$-tocopheryl polyethylene glycol succinate 2000 (Vitamin E TPGS(2k)) micelles for targeted and synergistic chemotherapy. Biomaterials, 2011; 32: 4058-4066.

32. Qu G, Yao Z, Zhang C, Wu X, Ping Q. PEG conjugated N-octyl-O-sulfate chitosan micelles for delivery of paclitaxel: In vitro characterization and in vivo evaluation. Eur. J. Pharmaceutic. Sci 2009: 37: 98-105 
33. Emami J, Rezazadeh M, Rostami M, Hassanzadeh F, Sadeghi H, Mostafavi A, et al. Co-delivery of paclitaxel and $\alpha$-tocopherol succinate by novel chitosan-based polymeric micelles for improving micellar stability and efficacious combination therapy. Drug Dev Ind Pharm, 2015; 41: 1137-1147.
34. Zhang Z, Tana S, Feng S. Vitamin E TPGS as a molecular biomaterial for drug delivery. Biomaterials, 2012: 33: 4889- 4906

35. Youk H, Lee E, Choi M, Lee Y, Chung J, Kim S, Lee Cha, Lim S. Enhanced anticancer efficacy of atocopheryl succinate by conjugation with polyethylene glycol. J. Control. Release, 2005:107 43-52 